Ege Journal of Medicine / Ege Tıp Dergisi 2015;54(2):86-88

\title{
Geç çocuklukta tanı konulan konjenital bir anomali: Morgagni hernisi
}

\section{A congenital anomaly diagnosed in late childhood: Morgagni hernia}

\author{
Abdulgani GÜLYÜZ ${ }^{1}$ Mehmet TEKIN ${ }^{2}$ Çapan KONCA ${ }^{2}$ Muhammed Ikbal YETiş ${ }^{3} \quad$ Mehmet DEMiRCAN $^{3}$ \\ ${ }^{1}$ Özel Sevgi Hastanesi, Çocuk Sağlığı ve Hastalıkları Kliniği, Malatya, Türkiye \\ ${ }^{2}$ Adıyaman Üniversitesi Tıp Fakültesi, Çocuk Sağlığı ve Hastalıkları Anabilim Dalı, Adıyaman, Türkiye \\ ${ }^{3}$ Inönü Üniversitesi Tıp Fakültesi, Çocuk Cerrahisi Anabilim Dalı, Malatya, Türkiye
}

\section{Öz}

Morgagni hernisi nadir görülen bir konjenital diyafragmatik herni türüdür ve çoğunlukla minimal bulgularla seyrettiği için ancak ileri yaşlarda tanı konulabilmektedir. Birçok olgu asemptomatik olduğu için, Morgagni hernisi literatürde söylendiğinden daha sık olabilir. Bu herniler bebek ve çocuklarda daha az görülmektedir. Çocuklarda majör bulgu tekrarlayan akciğer enfeksiyonları olmakla beraber nadiren yenidoğan döneminde akut solunum yetmezliği ile de karşımıza çıkabilmektedir. Yan grafi ile tanı konulabilir ve toraks tomografisi ile tanı kesinleştirilir. Genellikle asemptomatik seyretse de ileride gelişebilecek komplikasyonları önlemek amacıyla cerrahi onarım önerilmektedir. Burada iki hafta boyunca öksürük şikayeti bulunan ve Morgagni hernisi tanısı konan 14 yaşında bir erkek olgu sunulmaktadır.

Anahtar Sözcükler: Geç çocukluk, Morgagni hernisi, radyografi.

\section{Abstract}

Morgagni hernia is an uncommon type of congenital diaphragmatic hernia and usually diagnosed in older ages with minimal symptoms. However, hernia of Morgagni may be more frequent than the literature suggests since most cases are asymptomatic. These hernias are uncommon in infants and children. In children, the majority present with repeated pulmonary infections; rarely it might present in the neonatal period as acute respiratory distress syndrome. It is diagnosed with lateral chest radiography and confirmed with computarized tomography. Although most of these hernias are asymptomatic, surgical repair is recommended to avoid future complications. Herein we report a 14 yearold boy with Morgagni hernia which was diagnosed after two weeks ongoing cough.

Keywords: Late childhood, Morgagni hernia, radiography.

\section{Giriş}

Morgagni hernisi nadir görülen bir diyafragmatik herni türüdür (1). Çoğunlukla erişkin dönemde saptanan ve bu yaşlarda semptomsuz olan ya da kusma, ishal, kabızlık, şişkinlik gibi atipik semptomlarla seyredebilen bir doğumsal anomalidir (2). Çocuklarda saptanan olgularda ise genellikle solunum yolu problemleri ön plandadır. Doğumsal anomaliler sıklıkla yenidoğan döneminde bulgu verdiğinden daha sonraki dönemlerde şüpheci olunmadığı takdirde rahatıkla atlanabilmektedirler.

Yenidoğan döneminde solunum sıkıntısı nedeniyle yoğun bakımda yatan ancak daha sonra tekrarlayan akciğer enfeksiyonu öyküsü bulunmayan 14 yaşındaki hastanın iki haftadır geçmeyen öksürük şikayeti nedeniyle yapılan radyolojik inceleme ile Morgagni hernisi tanısı kondu.

Yazışma Adresi: Mehmet TEKIN

Adıyaman Üniversitesi Tıp Fakültesi, Çocuk Sağlı̆̆ı ve Hastalıkları Anabilim Dalı, Adıyaman, Türkiye

Makalenin Geliş Tarihi: 09.01.2014 Kabul Tarihi: 21.03.2014
Bu olgu, özellikle şüpheli akciğer lezyonlarının varlığında yan akciğer grafisi çekilmesi konusunda çocuklarla ilgilenen hekimlerin dikkatini çekmek amacıyla sunuldu.

\section{Olgu Sunumu}

On dört yaşında erkek hasta, bir haftadır devam eden öksürük, göğüs ağrısı, hafif ateş, kırgınlık şikayeti ile kliniğimize başvurdu. Hastanın özgeçmişinde yenidoğan döneminde solunum sıkıntısı nedeniyle yenidoğan yoğun bakım ünitesinde yatış, sık tekrarlayan tonsillit ve uzun zamandır devam eden kabızlık şikayeti mevcuttu. Daha önce geçirilmiş bir akciğer enfeksiyonu öyküsü yoktu. Aile öyküsünde özellik saptanmadı. Hastanın boy ve kilosu \%50 persantilde olup tansiyon arteriyel 112/74 $\mathrm{mmHg}$ idi. Fizik incelemede; farenks hiperemik, kalp sesleri normal, ritmik; üfürüm duyulmadı, solunum seslerinde kabalaşma, yer yer kaba raller, ekspiryumda hafif uzama izlendi. Akut bronşit tanısı ile makrolid grubu antibiyotik ve bronkodilatatör başlanan hasta ayaktan tedavi ile gönderildi. Bir hafta sonra öksürük şikayeti 
geçmediği için tekrar polikliniğimize başvuran hastanın göğüs ön bölümde, sağ altta solunum seslerinin azaldığı gözlendi, bunun üzerine akciğer grafisi çekildi. Ön-arka akciğer grafisinde sağ parakardiak bölgede demarkasyon hattı izlenen hastadan konjenital diyafragma hernisi, pnömoni, akciğerde kitle, atelektazi ön tanıları ile yan akciğer grafisi istendi (Şekil-1a). Tam kan sayımında lökosit değeri $12500 \mathrm{~mm}^{3} / \mathrm{L}, \quad$ CRP $2.58 \mathrm{mg} / \mathrm{dL}$, sedimantasyon hızı $22 \mathrm{~mm} / \mathrm{h}$ bulundu. Yan akciğer grafisinde poststernal bölgede, içinde barsak anslarının seçildiği düzgün sınırlı kitle saptanması üzerine diyafragma hernisi ön tanısıyla toraks bilgisayarlı tomografisi (BT) istendi (Şekil-1b). Toraks BT'de mediasten ön bölgedeki poststernal düzgün sınırlı kitlenin Morgagni hernisi ile uyumlu olduğu bildirildi (Şekil-1c). Hasta Çocuk Cerrahisi polikliniğine yönlendirildi. Çocuk Cerrahisi tarafından transabdominal laparoskopik yöntemle opere edildi.

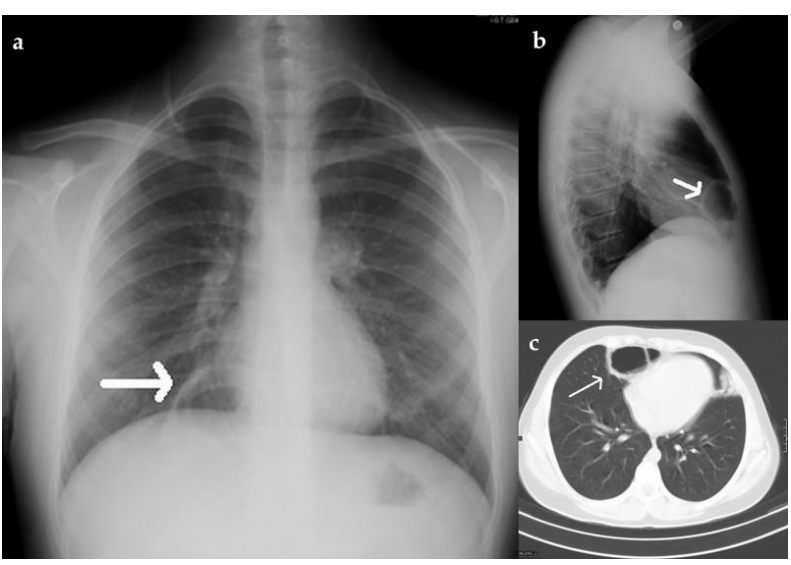

Şekil-1. a. Ön-arka akciğer grafisinde sağ parakardiak bölgede demarkasyon hattı. b. Yan akciğer grafisinde sternum arkasında içinde barsak anslarının izlendiği hern kesesi. c. Akciğer tomografisinde sağ akciğerde sternum arakasında içinde barsak ansları bulunan herni kesesi.

\section{Tartışma}

Konjenital diyafragma hernileri 2000 ile 5000 doğumda bir görülmekte ve bunların ancak \%2-6'sını Morgagni hernileri oluşturmaktadır (1). Morgagni hernisi ilk kez 1769 yılında İtalyan bir anatomist olan Giovanni Battista Morgagni tarafından yapılan bir otopside tanımlanmıştır (3). En sık görülen diyafragmatik herni türü olan Bochdalek hernisinde defekt posterior bölgede iken Morgagni hernisinde anterior bölgede oluşmaktadır. Diyafragmanın transvers septumunun sternuma yapışma bölgesindeki zayıflıktan kaynaklandığı düşünülmektedir. Lev-Chelouche ve ark (4), bu nedenle hastalığın çocuklarda daha az görüldüğünü ve obesite, gebelik gibi karın içi basıncın arttığı ilerleyen yaşlarda daha sık ortaya çıktığını ileri sürmüşlerdir. Retrosternal bölgede oluşan bu hernilerin \%90'ı sağ tarafta görülmektedir.

Volume 54 Issue 2, June 2015 / Cilt 54 Sayı 2, Haziran 2015
Bochdalek hernisi genellikle yenidoğan döneminde ağır solunum sıkıntısı ile bulgu verirken Morgagni hernisi semptomsuz seyretmekte ve çoğunlukla erişkin dönemde obezite, kronik öksürük, kronik kabızlık, gebelik gibi karın içi basıncın arttığı durumlarda bulgu vermektedir. Erişkinlerde semptomlar genellikle atipik olup kusma, karın ağrısı, şişkinlik gibi daha çok gastrointestinal sistemle ilgili bulgular olup çoğunlukla başka nedenlerle çekilmiş grafilerde tesadüfen tanı konmaktadır (5). Çocuklarda \%50 oranında subakut seyretmekte ve daha çok tekrarlayan akciğer enfeksiyonları ile karşımıza çıkmaktadır (6). Morgagni hernisi bulunan hastalarda Down sendromu, Noonan sendromu, konjenital kalp hastalıkları, mental retardasyon ve genitoüriner anomalilerin daha sık görüldüğü bildirilmiştir (5). Ön-arka akciğer grafisinde sağ ya da sol parakardiak bölgede düzgün sınırlı kitle imajı vermekte ancak herni kesesinin içinde kolon, mide, karaciğer bulunmasına göre görüntü değişebilmektedir. Yan grafiler tanı konmasında oldukça faydalı olup retrosternal bölgedeki düzgün sınırlı lezyon kolaylıkla seçilebilmektedir. Baryumlu grafiler, toraks BT, ultrason ve manyetik rezonans görüntüleme de kullanılabilmekle beraber günümüzde daha çok toraks BT ile tanı kesinleştirilmektedir (7). Ayırıcı tanıda mediastinal kitle, pnömoni, atelektazi, pnömotoraks düşünülmelidir. Biçer ve ark. (8), bir çocukta akciğer grafisinde pnömotoraks saptadıklarını ve ayırıcı tanı için yapılan ultrasonografide hastalarına Morgagni hernisi tanısı konulduğunu bildirmişlerdir. Tedavisiz olgularda akut barsak obstrüksiyonu, inkarserasyon, barsak perforasyonu gibi komplikasyonlar bildirilmiştir (9). Tedavisi cerrahidir. Semptomsuz olgularda operasyon tartışmalı olmakla beraber ileride gelişebilecek barsak obstrüksiyonu gibi komplikasyonları önlemek amacıyla tüm olgularda cerrahi müdahale önerilmektedir. Son dönemde transabdominal laparoskopik yöntemler tercih edilmektedir (10).

Morgagni hernisi konjenital bir herni olmasına rağmen, bizim olgumuzda da literatürde gösterildiği gibi bulgular geç dönemde ortaya çıkmış, hatta yenidoğan döneminde solunum sıkıntısı nedeniyle yoğun bakımda kaldığı halde herni ile ilgili herhangi bir bulguya rastlanmadığı anlaşılmıştır. Çocuklarda sık tekrarlayan akciğer enfeksiyonlarının görüldüğü bildirilmekle beraber, hastamızda daha önce akciğer enfeksiyonu öyküsü bulunmamakta idi. Hastamızda literatürde bildirildiği gibi karın içi basıncı arttıran bir olayın, yani kabızlığa bağlı şiddetli ıkınma nedeniyle herninin bulgu verdiğini düşünmekteyiz. Yine literatüre uygun olarak ön-arka akciğer grafisinde sağ parakardiak bölgedeki demerkasyon hattını daha iyi değerlendirmek için yan akciğer grafisi çekildi ve içinde barsak anslarının bulunduğu herniasyon kolaylıkla saptandı, arkasından toraks BT ile tanı kesinleştirildi.

Konjenital anomaliler çoğunlukla yenidoğan döneminde bulgu verdiklerinden yaşamın daha sonraki dönemle- 
rinde genellikle akla getirilmemektedirler. Morgagni hernisi çoğunlukla asemptomatik olduğu için gerçek sıklığı sanılandan çok daha fazla olabilir. Diyafragma hernilerinde kese içerisindeki lezyona göre görünüm çok değiştiğinden özellikle parakardiak bölgede izlenen lezyonların dikkatle incelenmesi ve mutlaka yan akciğer grafisi ile şüpheli lezyonların morgagni hernisi açısından değerlendirilmesi hem ucuz hem de hızlı ve kolay ulaşılabilir bir tanı yöntemi olarak önemini korumaktadır.

\section{Kaynaklar}

1. Loong TP, Kocher HM. Clinical presentation and operative repair of hernia of Morgagni. Postgrad Med J 2005;81(951):41-4.

2. Horton JD, Hofmann LJ, Hetz SP. Presentation and management of Morgagni hernias in adults: A review of 298 cases. Surg Endosc 2008;22(6):1413-20.

3. Pokorny WJ, McGill CW, Harberg FJ. Morgagni hernias during infancy: Presentation and associated anomalies. J Pediatr Surg 1984;19(4):394-7.

4. Lev-Chelouche D, Ravid A, Michowitz M, Klausner JM, Kluger Y. Morgagni hernia: Unique presentations in elderly patients. J Clin Gastroenterol 1999;28(1):81-2.

5. Aghajanzadeh M, Khadem S, Khajeh Jahromi S, Gorabi HE, Ebrahimi H, Maafi AA. Clinical presentation and operative repair of Morgagni hernia. Interact Cardiovasc Thorac Surg 2012;15(4):608-11.

6. Eren S, Ciris F. Diaphragmatic hernia: Diagnostic approaches with review of the literature. Eur J Radiol 2005;54(3):448-59.

7. Abraham V, Myla Y, Verghese S, Chandran BS. Morgagni-Larrey hernia - a review of 20 cases. Indian J Surg 2012;74(5):391-5.

8. Biçer S, Doğan A, Uzuner S ve ark. Pnömotoraks olarak yanlış tanı alan bir konjenital diyafragma hernisi olgusu. İst Tıp Fak Derg 2006;69(2):49-51.

9. Pfannschmidt J, Hoffmann H, Dienemann H. Morgagni hernia in adults: Result in 7 patients. Scand J Surg 2004;93(1):77-81.

10. Van Niekerk ML. Laparoscopic Morgagni hernia repair using single-site umbilical and full-thickness abdominal wall repair: Technical report of two cases. Afr J Paediatr Surg 2013;10(1):55-7. 